\title{
A confirmatory factor analysis of IS employee motivation and retention
}

\author{
Brenda L. Mak ${ }^{\mathrm{a}, *}$, Hy Sockel ${ }^{\mathrm{b}}$

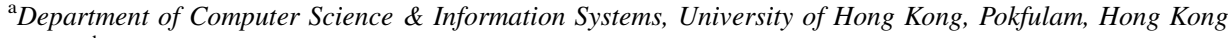 \\ ${ }^{\mathrm{b}}$ Computer and Information Science, Clevleand State University, Cleveland, OH 44115, USA
}

Received 18 August 1999; accepted 24 November 1999

\begin{abstract}
It is widely recognized that the relationships between organizations and their IS departments are changing. This trend threatens to undermine the retention of IS workers and the productivity of IS operations. In the study reported here, we examine IS employees' motivation and intent to remain using structural equation modeling. A survey was conducted among existing IS employees and analyzed with LISREL VIII. Results showed that latent motivation has an impact on latent retention, with job satisfaction and perceptions of management on career development as indicator variables for the former, and burnout, loyalty, and turnover intent as indicator variables for the latter. Implications for management in developing strategies for the retention of IS employees are provided. (C) 2001 Elsevier Science B.V. All rights reserved.
\end{abstract}

Keywords: Retention; Motivation; Turnover intent; Loyalty; Burnout; Job satisfaction; Perception of management; Career development

\section{Introduction}

IS employees are in high demand. In a Delphi study in conjunction with the Society of Information Management, Brancheau [7] found that the issue of 'Recruiting and Developing IS Human Resources' was rated as the eighth most important. Frazee [19] reported that 47 percent of a group of 434 CEOs of fast growing companies felt that the lack of skilled and trained workers is a potential barrier to company growth. Coopers and Lybrand indicate that qualified programmers, systems and networking professionals, and skilled computer personnel are most difficult to find. According to the U.S. Bureau of Labor Statistics,

\footnotetext{
* Corresponding author. Tel.: +852-2859-2171; fax: $+852-2559-8447$.

E-mail addresses: bmak@csis.hku.hk (B.L. Mak), hysockel@cis.csuohio.edu (H. Sockel).
}

the demand for Information Systems (IS) workers will increase by 95,000 people per year between 1994 and the year 2005 [25]. In all, business will generate a demand for an additional 1.3 million IS workers, resulting in a change of US\$ 500 billion a year in US business. The Information Technology Association of America (ITAA), a lobbying association that represents 11,000 organizations, updated their 1997 projected shortage of IS technologists from over 150,000-346,000 in 1998.

Shortage of IS programmers and analysts can cause important IS projects to be delayed. Sometimes they never become available or arrive too late, resulting in lost opportunities. At other times, projects are started, considerable energy is expended, but they are never finished because of lack of employee availability. Poor retention can be due to employee turnover, burnout, and lack of commitment. Turnover of employee should be well managed, because the people who 
leave may be among the best employees [37]. In other cases, even if the employees do not leave the lack of morale due to burnout or low commitment may mirror the problems caused by employee turnover [38]. Retaining a healthy team of committed and productive employees, therefore, is necessary to maintain a corporate strategic advantage.

Closely related to the issue of employee retention is their motivation. It is important to ensure employees work towards the goals of the organization. Three major theories are commonly used to explain this: (1) Maslow's Hierarchy of Needs Theory [36], (2) Herzberg's Dual Factor Theory [18] and (3) HackmanOldham's Job Characteristic Theory [27]. These theories share the concept that the fulfillment of needs is central to motivating employees, with motivators that increase satisfaction needing to be part of the job. Motivators are often viewed from the vantage of being internal or external. Internal motivators are concerned with the intrinsic needs satisfying the individual. They address special needs of the individual, such as growth, social approval, security, etc. External motivators are concerned with environmental factors brought by the organization to the individual. They are often regarded as manipulative and include praise, communication, benefits, or money. Ginzberg and Baroudi [24] indicate that most studies of IS personnel have centered on external factors. In this study we focus on IS development personnel and their motivation as it relates to internal motivators.

One of the challenges faced by IS developers is the constant change in technology. This exposes them to considerable job stress and fear of obsolescence $[2,44]$. On the one hand, they would like the company to adopt new technology so that they learn new skills. However, some have no desire or ability to keep up with technology. To motivate them, it is important that management help them with opportunities for career development. The motivation of the IS personnel to perform well is thus affected by their satisfaction with their job situation and the perception of the effectiveness of management policies on career development.

Past studies have addressed how job satisfaction [34] and perception of management policies on career development [21] are important motivators. In this study, we investigate how job satisfaction and perception of management policies act as observable measures for the latent construct of motivation to affect IS employee retention. We focus on the observable effects of retention: burnout, loyalty and turnover intention. We measure the turnover intent of existing employees in an organization rather than the actual turnover. We include both burnout and loyalty as elements of retention as they indicate the conditions of the retained employees. Loyalty is an antecedent of turnover intentions and turnover $[9,12]$ and burnout is correlated to intention to quit [55]. An employee suffering from burnout may cease to be productive [56].

The purpose of this article is to investigate the underlying dimensions of the motivation and retention constructs. As motivation and retention are not directly observable, we employ maximum likelihood confirmatory factor analysis to estimate and test measurement models incorporating indicator variables for these two latent constructs. Confirmatory factor analysis is a technique commonly used for the analysis of latent variables, and has been applied to analyze complex IS constructs [10]. We perform confirmatory factor analysis to investigate how job satisfaction, perception of management on career development, loyalty, burnout, and turnover intent, become indicator variables to the latent constructs of motivation and retention. We also examine the relationship between motivation and retention.

\section{Latent motivation and its effect on retention}

Motivation is an extremely important and complicated topic. It has been well studied, but strong disagreement persists. Three of the prominent theories on motivation are from Abraham Maslow [42], Fredrick Herzberg, and Hackman-Oldman. Maslow's theory deals with the psychological aspects of motivation while Herzberg's theory is concerned with the actual instruments that can be used as incentives for employees. Maslow theorizes a five level hierarchy of needs in an effort to explain motivators. He indicates that the lowest unmet need is the one that must be addressed to motivate an individual, and needs should be fulfilled in a hierarchical manner. His five levels from lowest to highest are: physiological, safety, social, esteem, and self-actualization.

Herzberg, on the other hand, divides factors into two groups consisting of five motivators and 11 hygienic factors. He argues that hygienic factors are 
a necessary but not sufficient condition to motivate individual. He says that decreasing hygienic factors would lead to dissatisfaction, but once awarded, additional items lose their capability to motivate. An example may be health insurance; rather than being an employee benefit, it has become a 'given' expected term within the constraints of the job. He concludes that factors (motivators) that make people happy are related to what people did, and factors (hygiene) that make people unhappy are related to how they are treated. Employees may still have poor satisfaction with hygiene factors even when their career satisfaction is high [23].

The Hackman-Oldham model identifies five core job dimensions: (1) Skill variety; (2) Task identity; (3) Task significance; (4) Autonomy; (5) Feedback from the job. The model proposes that a high degree of satisfaction in these dimensions will lead to a healthy critical psychological state, which in turn will lead to more favorable personal and work outcomes.

\subsection{Do IS and non-IS employees share the same motivating factors?}

A debate that has continued within the IS literature: 'Are IS and non-IS employees different?' Ferratt and Short found that both could be motivated equally using the same underlying constructs [15]. Im and Hartland disputed their methodology while supporting their outcome [30]. They argued that Ferratt and Short failed to examine the key issues and should have examined some 93 additional hypotheses before attacking the question whether the means for the three groups were different between employees. Ferratt and Short responded by indicating that Im and Hartland failed to grasp the subtlety of the study [17]. Nevertheless, Ferratt and Short did admit that their sample was not random and limited to a specialized group of employees in selected insurance companies in the Midwestern United States: thus they are not representative of all industries [16].

In contrast, other researchers found differences between IS and non-IS workers. Fitz-enz, using Herzberg's factors, surveyed over 1500 individuals and found a difference in the characteristics between the general public and programmers. Myers found that IS employees were distinct from the non-IS employee and there were significant differences between them in the area of needs. Sutherland states that the skills and competence required of information analysis are quite different from those required for organizational learning and strategic management [52].

Couger and Zawacki, applying Maslow's theory, showed that a person develops job satisfaction by comparing his or her situation with those of others in the same social group [11]. Using the HackmanOldham model, they surveyed the job perceptions of more than 6000 people from different professional areas and compared the data processors to the general public. They found that programmers found their work less meaningful and rated their jobs less favorably than other professionals. Their need to interact with others was almost insignificant. However, IS professionals displayed very high growth needs and were concerned about learning new technology.

\subsection{Motivating factor: job satisfaction}

Job satisfaction has traditionally been defined as a positive emotional state reflecting affective (fondness) attitude or response towards the job situation. It is an important motivator for employee performance; it is a causal antecedent to organizational commitment [39], and negatively related to turnover [6,54] and absenteeism [40].

Previous research has found correlation in the range of 0.50 between job satisfaction and job involvement, job satisfaction and organizational commitment, or job involvement and organization commitment [8]. Poulin found that the organizational work environment had a significant impact on social worker's overall job satisfaction. In addition, change in professional development opportunities was positively associated with increased job satisfaction [46,47].

Within the IS arena, satisfaction has been found to be related to turnover and performance [29]. Blankertz and Robinson [5] demonstrated that employees with high job satisfaction are highly motivated and have little desire to leave their jobs. Thus, job satisfaction is a key factor for employee motivation.

\subsection{Motivating factor: perception of management on career development}

Facteau et al. [14] found that support of subordinate, superior and top management is predictive of 
employee motivation. Babin and Boles [3] found that perceptions of supervisory support could increase satisfaction and motivation, reducing stress and improving job performance. Thus, management support has a significant impact on employee motivation.

Crepeau et al. [13] studied the management issues among IS professionals via the Career Orientations Inventory. They noted that, because of changes in IS growth and promotions, there will be a greater focus on effective management of IS professionals. They stated that some IS career management strategies have been associated with problems, and have led to higher levels of employee burnout and turnover. Further they indicated that those vested in managing IS personnel recognize that more attention toward career development is needed. They concluded that management actions and style can play a key aspect relative to the motivation and retention of IS employees.

Griesser [26] investigated the motivational issues among IS professionals. He noted that IS employees are more resistant to changes than other professionals, and development professionals are concerned about their career development prospect. IS developers are faced with the constant change of technology. Some may fear obsolescence of their skills; others may be frustrated with constantly needing to learn new technology. To help employees overcome this fear, managers should introduce programs offering IS employees chances for career development. Employees' perception of management policies on career development has an important impact on their motivation.

\section{The retention construct}

Companies with better organization culture have better retention rates [51]. Mone says that as management shuffles the organization by reorganizing, downsizing, and eliminating layers of workforce, there is a direct impact on the employees of the organization. One of the dysfunctional consequences of downsizing is that survivors of the shrinkage get nervous, experiencing increased stress and job insecurity. Mone suggests that it is not always the poorest performers who leave; in fact it is often the highest performing workers who find good alternatives and are the first to leave. To improve retention, the company should adopt career development policies in alignment with the needs of the employees. This would motivate IS employees and overcome their job stress and fear of obsolescence.

Retention is really a construct and not just one variable. Researchers focus on different aspects. For example, Muhammad found that stressors, such as work overload and role ambiguity, might cause the employee to have low job satisfaction and motivation, subsequently resulting in low organizational commitment, burnout and high turnover [41].

Thus we believe that retention can manifest itself in three ways:

1. The employee may decide that his or her needs can no longer be met by the organization and develop an intention to leave the firm or change career path;

2. The employee may develop an enhanced sense of loyalty and commitment to the organization;

3. The employee may be so stressed that he or she may turn into 'burn-out' mode, when the employee ceases to contribute effectively to the organization.

\subsection{Retention effects: turnover}

Employee turnover is a critical problem for IS departments. The skills of their employees are hard to acquire and require substantial training. Staff experience is a necessity in maintaining work quality. Szajna [53] and Ravichandran [49] point out that 25 percent of the project failures can be attributed to programmer turnover. Indeed, turnover may lead to a loss of human resources weakening competitive positions.

While employees with low turnover tendency are characterized by high job satisfaction and job security perceptions [20], employees with high turnover intent may be filled with frustration and may not concentrate on their jobs. We measure turnover intent of existing employees; this indicates the degree of contribution of the employees. Campion suggests that the measures should be viewed as lying on a continuum rather than on one of the two ends. Lower employee turnover intent may indicate better employee retention.

\subsection{Retention effects: burnout}

Burnout is related to turnover intent and is an indicator of the degree of employee contribution. 
When the employee is no longer committed to the work environment but is only going through the motions of work mechanics there is extreme stress. An organizational culture that becomes too stressful, abusive, inconsistent with its employees' needs and desires may experience personnel burnout. Physical and emotional exhaustion may increase this risk, which may become debilitating, with depression, internal personal problems, and mental or physical illness.

Muhammad found that work stressors, such as work overhead, role ambiguity, conflict and resource inadequacy, were significantly related to 'burnout' symptoms in the form of psychosomatic health problems, when though the employee is not entertaining the concept of leaving, the organization is no longer getting proper benefits from the employee.

Burnout is a problem for IS employees. The pressure to keep up with the technology creates stress. The demands from the user communities also challenge the IS group, giving rise to more stress [22]. IS employees may find themselves forced to perform well; otherwise projects are outsourced, with a cutback in the company's own IS department. Employees may misinterpret this change in personnel as a prelude to a reduction in workforce. This fear may render the employee insecure and stressed and may eventually lead to burnout.

\subsection{Retention effects: loyalty}

Loyalty loss is an antecedent of turnover intentions. Loyalty, or organizational commitment, has most commonly been studied as attitudinal or affective; it may be defined as a relative strength of individuals' identification with the involvement in a particular organization.

Commitment has also been studied from a behavioral perspective, as proposed by Salancik [50]. Behavioral commitment is tied to some future outcome and defined in terms of the cost to leave the organization. Salancik's view is derived primarily from the commitment model of Kiesler [33], where the focus is on behavior. Essential conditions are explicitness, revocability, volition and publicity. One example is employees' response to improve communication [43] and performance.

\section{Methodology}

\subsection{Sample selection}

After developing and piloting a questionnaire to investigate the latent constructs of motivation and retention, the modified survey questionnaires were sent to individual groups of professionals in the US Midwest. The sample consisted of a diverse population of IS employees from all levels of organizations developing IS. These include organizations from aerospace, military, finance, insurance, manufacturing, accounting, publishing, government, utilities, education, healthcare, construction, transportation, entertainment, retail, software development, and data processing services. Due to the sensitive nature of the questions, all respondents were guaranteed anonymity, and no specific data that might identify the client was solicited. In all, slightly more than 300 questionnaires were distributed while 130 responses were returned. Twelve surveys were disqualified for lack of completeness leaving 118 usable for data analysis. Thus the response rate was 39 percent. This sample size of more than 100 was sufficient for structural equation modeling with LISREL analysis, as noted by Jackson et. al. [31]

“...Hayduk [28] suggested that a sample size of

100 normally provides stable estimates...determining an adequate sample size depends on such factors as (1) the rank of the input matrix, and (2) the complexity of the hypothesized model. Boomsma cautioned that small samples potentially yield biased estimates of parameters and confidence intervals, and noted that samples of $n=100$ are adequate when the model has a simple structure and large factor loadings..."

The sample consisted of a diverse group of developers from different sizes of IS departments evenly distributed over five categories (from under five people to over 99 people), indicating that our sample is representative. About 35 percent worked in IS department of size under 14, 25 percent in departments of 15-49 people, 12.2 percent in departments of 50-99 people, and 25 percent in departments of over 99 people. More than 82 percent of the respondents were between 25 and 45 years old. Over 61 percent had 2-10 years of employment with their current 
organization. 61 percent of the respondents identified their functional responsibility as System analyst, Programmer, or Project leader. Less than 22 percent of the respondents had less than 2 years IS experience while over 26 percent had more than 10 years experience. The respondents were distributed across a variety of different development platforms, 65 percent of the respondents had been college trained. A detailed analysis of our data indicated that 83 percent of the employees viewed technology as an aid. In addition, 45 percent of the respondents indicated they would work for less money to learn new technology. Their normal work activities were concentrated on new development, enhancements, and maintenance work. This is a group with a strong predisposition to introduction of new technologies for career development.

\subsection{Research instrument}

The survey instrument was created after conducting literature reviews and in depth interviews with several IS directors. The scales were patterned after existing instruments, specifically Porter's Organizational Commitment Questionnaire [39], the Burnout questionnaire of Pines and Aronson [45], Hackman and Oldham's satisfaction scale, and INFO World registration forms. In particular the 'Intent to leave' scale is modeled following the scale of Igbaria and Larson [35]. Preliminary versions of this questionnaire were reviewed and discussed by peers and practitioners within the IS community.

The items in the questionnaire are given in Table 1. The validity of the construct is established by conducting confirmatory factor analysis (CFA) [1]. We

Table 1

Items within the questionnaire

\begin{tabular}{|c|c|c|}
\hline Construct & Items & Questions \\
\hline \multicolumn{3}{|l|}{ Motivation factors } \\
\hline \multirow[t]{4}{*}{ Job Satisfaction } & sat01 & All in all, I am satisfied with my job \\
\hline & sat02 & In general, I like working here \\
\hline & sat03 & I will probably not be looking for a job outside of Information Services/software/data processing \\
\hline & sat04 & I seldom think about quitting \\
\hline Perception of & hr01 & My organization makes a real effort to develop the employee's skills \\
\hline Management on Career & hr02 & My firm has a sound program to attract qualified people \\
\hline \multirow[t]{2}{*}{ Development } & hr03 & I can detect a clear relationship between job performance and rewards \\
\hline & hr04 & My organization is paternal \\
\hline \multicolumn{3}{|l|}{ Retention factors } \\
\hline \multirow[t]{10}{*}{ Burnout } & str01 & Feeling depressed \\
\hline & str02 & Being physically exhausted \\
\hline & str03 & Being emotionally exhausted \\
\hline & str04 & Can't take it anymore \\
\hline & str05 & Feeling trapped \\
\hline & str06 & Feeling worthless \\
\hline & str07 & Feeling weary \\
\hline & str08 & Being troubled \\
\hline & str09 & Feeling hopeless \\
\hline & str10 & Feeling rejected \\
\hline \multirow[t]{4}{*}{ Loyalty } & loy01 & My values and that of the organization are very similar \\
\hline & loy02 & This organization inspires the best in me in the way of job performance \\
\hline & loy 03 & I am really glad that I work for this organization \\
\hline & loy04 & I would encourage a friend to work for my company \\
\hline \multirow[t]{4}{*}{ Turnover Intent } & $\operatorname{trn} 01$ & I am actively/passively looking for another job outside of my company's IS\&T department \\
\hline & $\operatorname{trn} 02$ & I would consider leaving for a company that had excellent project management \\
\hline & $\operatorname{trn} 03$ & I would seriously consider leaving for even a slightly better position elsewhere \\
\hline & $\operatorname{trn} 04$ & I would seriously consider leaving my job for a position where I could earn more \\
\hline
\end{tabular}


Table 2

Reliability of the items in the model

\begin{tabular}{|c|c|c|c|}
\hline Construct & Items & $\begin{array}{l}\text { Correlation with } \\
\text { criterion }\end{array}$ & $\begin{array}{l}\text { Corrected item total } \\
\text { correlation }\end{array}$ \\
\hline \multicolumn{4}{|l|}{ Motivation factors } \\
\hline \multirow[t]{4}{*}{ Job satisfaction } & Sat01 & 0.85 & 0.75 \\
\hline & Sat02 & 0.83 & 0.73 \\
\hline & Sat03 & 0.65 & 0.45 \\
\hline & Sat04 & 0.80 & $\begin{array}{l}0.67 \\
\alpha=0.89\end{array}$ \\
\hline \multirow[t]{5}{*}{ Perception of management on career development } & hr01 & 0.84 & 0.69 \\
\hline & hr02 & 0.86 & 0.72 \\
\hline & hr03 & 0.86 & 0.71 \\
\hline & hr04 & 0.64 & 0.45 \\
\hline & & & $\alpha=0.81$ \\
\hline \multicolumn{4}{|l|}{ Retention factors } \\
\hline \multirow[t]{5}{*}{ Loyalty } & Loy01 & 0.79 & 0.64 \\
\hline & Loy02 & 0.87 & 0.75 \\
\hline & Loy03 & 0.87 & 0.78 \\
\hline & Loy04 & 0.87 & 0.73 \\
\hline & & & $\alpha=0.87$ \\
\hline \multirow[t]{11}{*}{ Burnout } & Str01 & 0.77 & 0.71 \\
\hline & Str02 & 0.56 & 0.62 \\
\hline & Str03 & 0.61 & 0.64 \\
\hline & Str04 & 0.83 & 0.77 \\
\hline & Str05 & 0.83 & 0.73 \\
\hline & Str06 & 0.86 & 0.79 \\
\hline & Str07 & 0.68 & 0.69 \\
\hline & Str08 & 0.67 & 0.68 \\
\hline & Str09 & 0.87 & 0.84 \\
\hline & Str10 & 0.89 & 0.81 \\
\hline & & & $\alpha=0.94$ \\
\hline \multirow[t]{5}{*}{ Turnover intent } & $\operatorname{Trn} 01$ & 0.82 & 0.61 \\
\hline & $\operatorname{Trn} 02$ & 0.72 & 0.51 \\
\hline & $\operatorname{Trn} 03$ & 0.82 & 0.65 \\
\hline & Trn04 & 0.75 & 0.59 \\
\hline & & & $\alpha=0.78$ \\
\hline
\end{tabular}

performed validity checks for all the scales along four major dimensions: content validity, convergent validity, discriminant validity, and criterion-related validity. Before conducting construct validity analysis, the scales were checked for unidimensionality and statistical reliability (Table 2).

Content validity refers to whether the scale representatively measures the concept it is intended to measure. Since we derived many of the items in our questionnaire through a comprehensive study of relevant literature and existing instruments, the content validity of our instrument was established.
Unidimensionality is a necessary condition for reliability analysis and construct validation. We demonstrate the unidimensionality of our constructs by specifying a measurement model for each construct and by examining how well the constituting items represent the same construct. A goodness of fit index (GFI) of 0.90 or above suggests each of the constructs is unidimensional [32]. As shown in Table 3, all the five constructs have GFI ranging from 0.85 to 1.00 .

Reliability refers to the degree of stability of the scale. It is demonstrated by checking the Cronbach's alpha for the items in each question and the correlation 
Table 3

Scale unidimensionality, reliability, and convergent validity indices

\begin{tabular}{|c|c|c|c|c|}
\hline Construct & $\begin{array}{l}\text { Number } \\
\text { of items }\end{array}$ & $\begin{array}{l}\text { Goodness of fit } \\
\text { index (GFI) }\end{array}$ & $\begin{array}{l}\text { Cronbach's } \\
\text { alpha }(\alpha)\end{array}$ & $\begin{array}{l}\text { Bentler Bonett } \\
\text { coefficient (NFI) }\end{array}$ \\
\hline \multicolumn{5}{|l|}{ Motivation factors } \\
\hline Job satisfaction & 4 & 0.99 & 0.89 & 0.98 \\
\hline Perception of management on career development & 4 & 0.99 & 0.81 & 0.99 \\
\hline \multicolumn{5}{|l|}{ Retention factors } \\
\hline Loyalty & 4 & 0.93 & 0.87 & 0.93 \\
\hline Burnout & 10 & 0.85 & 0.94 & 0.85 \\
\hline Turnover intent & 4 & 1.00 & 0.78 & 1.00 \\
\hline
\end{tabular}

of the items with the criterion. The criterion variable of each construct is obtained by averaging the items in each question. Typically, a scale is said to be reliable if its Cronbach's alpha is 0.70 or higher. All the constructs have Cronbach's alpha ranging from 0.78 to 0.94 .

Convergent validity refers to the proximity of the results of different approaches to the same problem. This is examined by using the Bentler-Bonett normed fit index (NFI) [4]. This is the ratio of the difference between the $\chi^{2}$ value of the null measurement model $\left(C_{\mathrm{b}}\right)$ and the $\chi^{2}$ of the specified measurement model $(C)$ to the $\chi^{2}$ value of the null model i.e. $\mathrm{NFI}=$ $\Delta=\left(C_{\mathrm{b}}-C\right) / C_{\mathrm{b}}=1-C / C_{\mathrm{b}}$. A scale with NFI of 0.90 or above shows strong convergent validity. All of the scales except Burnout have NFI values above 0.90. Burnout has an NFI value of 0.85 , which is close to 0.90 . Accordingly, all the scales have strong convergent validity.

Discriminant validity of the scale refers to whether the item in one scale is distinguished from a construct of another scale. In order to establish discriminant validity, confirmatory factor analysis was performed on a selected pair of scales, allowing for correlation between the two constructs. The analysis was rerun with the correlation between the two constructs fixed at one. If the correlation is a free parameter and not this fixed constant, the chi-square of the initial model (where correlation is free) should be much smaller than the latter model (where it is fixed at one). In addition, the difference between the $\chi^{2}$ of these two models should be significant when checked against the chi-square test statistic at $p \leq 0.01$ with degrees of freedom equal to the difference in degrees of freedom between the two models. We performed the checks on every pair of the five scales. Altogether a total of 10 discriminant validity checks were run. All of these tests showed chi-square differences statistically significant at $p \leq 0.01$.

\section{Results of analysis}

Fig. 1 shows the model relationships as well as the fit measures for the model. The adequacy of the model was assessed using a number of fit measures [48]. In using structural equation models for testing, the null hypothesis is set up in such a way that a prior one expects that the null not be rejected. The chi-square statistic tests the hypothesis that the proposed model has generated the observed data, and a smaller $\chi^{2}$ value indicates a better fit. This means that when the chisquare values are statistically insignificant, the observed data can be closely patterned by the hypothesized model. However, due to sensitivity to sample size and departure from normality, the chi-squares are not good indicators of model fit. Instead, the chisquares per degrees of freedom are assessed and a ratio of five or less suggests a reasonable fit. The ratio of 3.85 in Fig. 1 indicates a reasonable model fit.

Other measures of model fit include goodness of fit index (GFI) and normed fit index (NFI). Both are always between zero and one, where one indicates a perfect fit, and any value above 0.9 a good fit. The model has a GFI of 0.94 and a NFI of 0.92 , suggesting a good fit. The adjusted goodness of fit (AGFI) is 0.78 , close to 0.8 and also shows a good fit. Similarly, nonnormed fit index (NNFI) and comparative fit index (CFI) are two additional measures ranging from zero to one, with values close to or greater than 0.9 


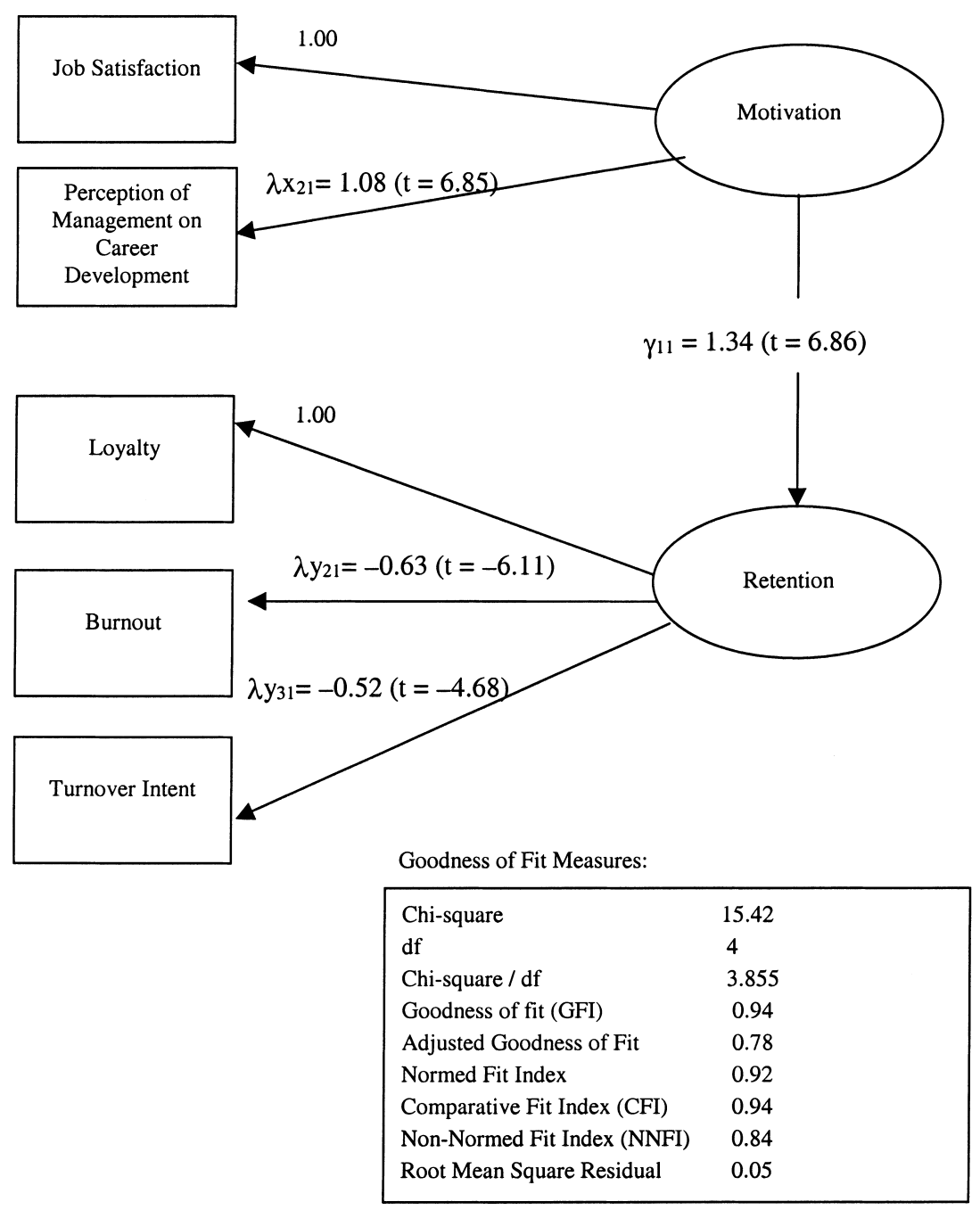

Fig. 1. LISREL path diagram for motivation and job retention.

representing a reasonable model fit. The NNFI and CFI for the model are 0.84 and 0.94 respectively. Finally, the root mean square residual (RMSR) shows the proportion of the variance not explained by the model. In general, a root mean square of 0.05 or below indicates a good model fit. The model has a RMSR of 0.05 . Thus these tests indicate the model has a good fit.

The maximum likelihood parameter estimates and $\mathrm{t}$-values are shown on the model in Fig. 1. $\lambda x_{11}$ and $\lambda y_{21}$ are set to one to define the unit of measurement for Motivation and Retention. As indicated, $\lambda x_{21}$ $(t=6.85)$ is 1.08 and is significant at the 0.01 level, demonstrating job satisfaction and perception of management on career development are observable indicators for Motivation. Since $\lambda x_{21}$ is greater than one, this suggests that Perception of Management on Career Development is a more important indicator than Job Satisfaction for Motivation. Similarly, $\lambda y_{21}$ $(t=-6.11)$, and $\lambda y_{31}(t=-4.68)$ are significant at the 0.01 level, showing that Burnout, Loyalty, and Turnover Intent are observable indicators for Retention. $\lambda y_{21}$ and $\lambda y_{31}$ are -0.63 and -0.52 , respectively, showing that the most important indicator of Retention is Loyalty, while Burnout and Turnover Intent are less important indicators. A high level of Retention is associated with a high level of Loyalty, and low levels 
of Burnout and Turnover Intent. In addition, $\gamma_{11}$ is 1.34 and is significant at 0.01 level $(t=6.86)$, showing motivating employees has important repercussions on their retention, with one unit increase in Motivation leading to 1.34 units increase in Retention.

\section{Discussion and conclusions}

In this study, we have investigated the relationship between IS employee motivation and IS employee retention using confirmatory factor analysis, and explored how these two latent constructs are indicated by job satisfaction, perception of management on career development, loyalty, burnout, and turnover intent.

The results of the confirmatory factor analysis shows that Job satisfaction and Perception of Management on Career Development are two important indicators for the Motivation construct, while loyalty, burnout and turnover intent are the indicators for the Retention construct. The results also show that the Motivation construct is highly correlated to the Retention construct.

One interesting observation was that while Burnout and Loyalty had high negative correlation (correlation $=-0.45$ ), and Turnover Intent and Loyalty had high negative correlation (correlation $=-0.53$ ), Turnover and Burnout did not have high correlation (correlation $=0.22$ ).

In developing structural equation model analysis, inappropriate conclusions may be drawn if criteria are permitted to drive analysis and override theory. Thus, the measurement model that postulates the relationship between observed measures and their underlying constructs must be reliable and valid. To ensure the internal validity of our model constructs, we pilot tested questionnaires and conducted reliability analysis, convergent, and discriminant validity checks. Care was taken to obtain a sufficiently large random sample to ensure normality of the research data and to reduce the effect of individual subject psychological bias.

We have found that job satisfaction is an important motivator. In addition, our results demonstrate the importance of perception of management policies on career development as a motivator affecting IS employee retention. Our results suggest that IS professionals are concerned about their career development prospect. Our sample consists of IS employees responsible for development, enhancement, and general support. Most of them consider career development a priority motivational tool. Once motivated, they would be devoted to their job and the company's retention rate would improve.

In addition, our results also provide additional insight on management strategy for IS managers. IS employees are interested in long-term security, good benefits and job protection. Proactive assignment by management of IS workers can increase employee loyalty, decrease employee dissatisfaction, absenteeism and turnover. To improve retention of IS employees, a company should adopt appropriate career development policies, such as arranging training workshops and seminars or offering incentives for learning new technology, in order to help employees overcome fear of obsolescence and motivate them to contribute to the organization.

\section{References}

[1] S.L. Ahire, D.Y. Golhar, M.A. Waller, Development and validation of TQM implementation constructs, Decision Sciences 27 (1), 1996, pp. 23-56.

[2] S. Aryee, Combating obsolescence: predictors of technical updating among engineers, Journal of Technology Management 8, 1991, pp. 103-119.

[3] B.J. Babin, J.S. Boles, The effects of perceived co-worker involvement and supervisor support on service provider role stress, performance and job satisfaction, Journal of Retailing 72 (1), 1996, pp. 57-75.

[4] P.M. Bentler, D.G. Bonett, Comparative fit indices in structural models, Psychological Bulletin 107 (2), 1990, pp. 238-246.

[5] L.E. Blankertz, S.E. Robinson, Who is psychosocial rehabilitation worker? Psychiatric Rehabilitation Journal 19 (4), 1996, pp. 3-13.

[6] A. Boomsma, Nonconvergence, improper solutions, and starting values in LISREL maximum likelihood estimation, Psychometrica 50 (2), 1985, pp. 229-242.

[7] J.C. Brancheau, B.D. Janz, J.C. Wetherbe, Key issues in information systems management: 1994-95 Sim Delphi results, MIS Quarterly 20 (2), 1996, pp. 225-242.

[8] P.P. Brooke Jr., D.W. Russell, J.L. Price, Discriminant validation of measures of job satisfaction, job involvement and organizational commitment, Journal of Applied Psychology 73 (2), 1988, pp. 139-145.

[9] M. Campion, Meaning and measurement of turnover: comparison of alternative measures and recommendations for research, Journal of Applied Psychology 76 (2), 1991, pp. 199-212. 
[10] W.W. Chin, P.A. Todd, On the use, usefulness, and ease of use of structural equation modeling in MIS research: a note of caution, MIS Quarterly 19 (2), 1995, pp. 237-246.

[11] J.D. Couger, R.A. Zawacki, What motivates DP professionals? Datamation 24 (9), 1978, pp. 116.

[12] D. Cramer, Job satisfaction and organizational continuance commitment: a two-wave panel study, Journal of Organizational Behavior 17 (4), 1996, pp. 389-400.

[13] R.G. Crepeau, C.W. Crook, M.D. Goslar, M.E. McMurtrey, Career anchors of information systems personnel, Journal of Management Information Systems 9 (2), 1992, pp. 145-160.

[14] J.D. Facteau, G.H. Dobbins, J.E.A. Russell, R.T. Ladd, The influence of general perceptions of the training environment on pretraining motivation and perceived training transfer, Journal of Management 21 (1), 1995, pp. 1-25.

[15] T.W. Ferratt, L.E. Short, Are information systems people different: an investigation of motivational differences, MIS Quarterly 10 (4), 1986, pp. 377-387.

[16] T.W. Ferratt, L.E. Short, Are information systems people different: an investigation of how they are and should be managed, MIS Quarterly 12 (3), 1988, pp. 427-443.

[17] T.W. Ferratt, L.E. Short, Patterns of motivation: beyond differences between IS and non-IS people, MIS Quarterly 14 (1), 1990, pp. 3-4.

[18] J. Fitz-enz, Who is the DP professional? Datamation 24 (9), 1978, pp. 125-128.

[19] V. Frazee, Skilled workers are in short supply, Personnel Journal 75 (11), 1996, pp. 23.

[20] K.N. Gaertner, S.D. Nollen, Turnover intentions and desire among executives, Human Relations 45 (5), 1992, pp. 447-465.

[21] M.J. Gallivan, Reskilling IS professionals: individual and organizational adaptation to software process innovations, in: Proceedings of the 1995 ACM SIGCPR Conference, ACM, New York, USA, 1995, viii+262, 103-116.

[22] R. Garner, D. Weldon, The numbers game, Computerworld 32 (4), 1998, pp. 88-93.

[23] G.G. Garske, The relationship of self-esteem to levels of job satisfaction of vocational rehabilitation professionals, Journal of Applied Rehabilitation Counseling 27 (2), 1996, pp. 19-22.

[24] M.J. Ginzberg, J.J. Baroudi, MIS careers-a theoretical perspective, Communications of the ACM 31 (5), 1988, pp. 586-594.

[25] T. Gregson, Communication satisfaction: a path analytic study of accountants affiliated with CPA firms, Behavioral Research in Accounting 2, 1990, pp. 32-49.

[26] J.W. Griesser, Motivation and information systems professionals, Journal of Managerial Psychology 8 (3), 1993, pp. 21-30.

[27] J.R. Hackman, G.R. Oldham, Work Redesign, AddisonWesley, Reading, MA, 1980.

[28] L.A. Hayduk, Structural Equation Modeling with LISREL: Essentials and Advances, The John Hopkins University Press, Baltimore, MD, 1980.

[29] M. Igbaria, T. Guimaraes, Antecedents and consequences of job satisfaction among information center employees, Journal of Management Information Systems 9 (4), 1993, pp. 145174.
[30] J.H. Im, S. Hartman, Rethinking the issue of whether IS people are different from non-IS people, MIS Quarterly 14 (1), 1990, pp. 1-2.

[31] C. Jackson, S. Chow, R.A. Leith, Toward an understanding of the behavioral intention to use an information system, Decision Sciences 28 (2), 1997, pp. 357-389.

[32] K.G. Jöreskog, D. Sörbom, LISREL 7: A Guide to the Program and Applications, 2nd Edition, SPSS, 1989.

[33] C.A. Kiesler, The Psychology of Commitment: Experiments Linking Behavior to Belief, Academic Press, New York, 1971.

[34] K. Klenke, K. Kievit, Predictors of leadership style, organizational commitment and turnover of information systems professionals, in: Proceedings of the 1992 ACM SIGCPR Conference, ACM, New York, USA, 1992; v+393, $171-83$

[35] L.L. Larson, Internal auditor job stress and turnover intentions, unpublished dissertation, Cleveland State University, 1996.

[36] A.H. Maslow, Motivation and Personality, Harper \& Row, New York, 1987.

[37] M.A. Mone, Relationships between self-concepts, aspirations, emotional responses, and intent to leave a downsizing organization, Human Resource Management 33 (2), 1994, pp. 281-298.

[38] J.E. Moore, A causal attribution approach to work exhaustion: the relationship of causal locus, controllability, and stability to job-related attitudes and turnover intention of the work exhausted employee (burnout), unpublished dissertation, Indiana University, Business Administration Management, 1997.

[39] R.T. Mowday, L.W. Porter, R.M. Steers, Employee-Organization Linkages: The Psychology of Commitment, Absenteeism and Turnover, Academic Press, New York, 1982.

[40] P.M. Muchinsky, Employee absenteeism: a review of the literature, Journal of Vocational Behavior 10 (3), 1977, pp. 316-340.

[41] J. Muhammad, Relationship of job stress and type-A behavior to employees' job satisfaction, organizational commitment, psychosomatic health problems, and turnover motivation, Human Relations 43 (8), 1990, pp. 727-738.

[42] M.E. Myers, An examination of motivations in the information systems profession, unpublished doctoral dissertation, University of Texas, Austin, 1989.

[43] C. Orpen, The effect of organizational commitment on the relationship between communication quality and managerial attitudes, Psychological Studies 40 (1), 1995, pp. 60-64.

[44] A. Pazy, Cognitive schemata of professional obsolescence, Human Relations 47 (10), 1994, pp. 1167-1199.

[45] A.M. Pines, E. Aronson, Career Burnout: Causes and Cures, The Free Press, New York, 1988.

[46] J.E. Poulin, Job satisfaction of social work supervisors and administrators, Administration in Social Work 19 (4), 1995, pp. $35-49$.

[47] J.E. Poulin, Job task and organizational predictors of social worker job satisfaction change: a panel study, Administration in Social Work 18 (1), 1994, pp. 31-38. 
[48] A. Rai, R. Patnayakuni, A structural model for CASE adoption behavior, Journal of Management Information Systems 13 (2), 1996, pp. 205-234.

[49] R. Ravichandran, U. Nazim, Offshore systems development, Information and Management 24 (1), 1993, pp. 33-40.

[50] G.R. Salancik, Commitment is too easy! Organizational Dynamics 6 (1), 1977, pp. 62-71.

[51] J.E. Sheridan, Organizational culture and employee retention, Academy of Management Journal 35 (5), 1992, pp. 10361056.

[52] E. Sutherland, Strategic management and information systems: an ambiguous relationship, International Journal of Information Resource Management 3 (2), 1992, pp. 24-32.

[53] A.B. Szajna, R.W. Scamell, The effects of information system user expectations on their performance and perceptions, MIS Quarterly 17 (4), 1993, pp. 493-516.

[54] E.A. Ward, Relation of job satisfaction and job knowledge and their effect on intention to turnover, Psychological Reports 63 (2), 1988, pp. 611-615.

[55] J. Weisberg, A. Sagie, Teachers' physical, mental, and emotional burnout: impact on intention to quit, Journal of Psychology 133 (3), 1999, pp. 333-339.

[56] J. Winnubst, Organizational structure, social support and burnout, in: W.B. Schaufeli, C. Maslach, T. Marek (Eds.), Professional Burnout: Recent Developments in Theory and Research, Taylor \& Francis, New York 1993, pp. 151-162.

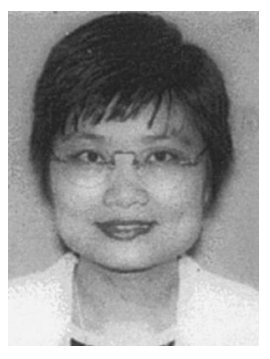

Brenda L. Mak is Assistant Professor in the Department of Computer Science and Information Systems in the University of Hong Kong. She holds as MS in Industrial Administration from Carnegie-Mellon University, as MS in Statistics and $\mathrm{PhD}$ in Business from Northwestern University. Dr. Mak has published in IEEE Transactions on Systems, Man, and Cybernetics, Information \& Management, Information, Processing, \& Management, Computers \& Graphics, Expert Systems with Applications, and others. Her research interests include data mining, knowledge discovery, decision making theories, genetic algorithms, and neural networks.

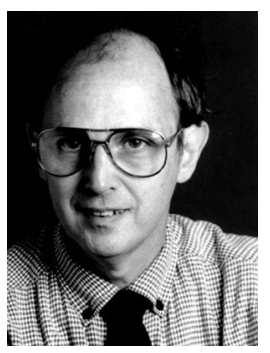

Hy Sockel is an associate professor of MIS with the Department of Management at Youngstown State University. He received his doctorate (DBA) from Cleveland State University. He has a wide range of research interests that include organizational management, database integration and networks. 